\title{
High HPV16 E6 viral load in the oral cavity is associated with an increased number of bacteria: A preliminary study
}

\author{
HIDEO SHIGEISHI $^{1}$, MASARU SUGIYAMA ${ }^{1}$, KOUJI OHTA ${ }^{2}$, SHO YOKOYAMA ${ }^{2}$, MIYUKI SAKUMA ${ }^{2}$, \\ HIROSHI MUROZUMI ${ }^{2}$, HIROKI KATO ${ }^{2}$ and MASAAKI TAKECHI ${ }^{2}$
}

\author{
${ }^{1}$ Department of Public Oral Health, Program of Oral Health Sciences, and ${ }^{2}$ Department of Oral and Maxillofacial Surgery, \\ Program of Dentistry, Graduate School of Biomedical and Health Sciences, Hiroshima University, Hiroshima 734-8553, Japan
}

Received October 14, 2017; Accepted November 13, 2017

DOI: $10.3892 / \mathrm{br} .2017 .1025$

\begin{abstract}
In a previous study, the present research group reported that males had a significantly higher prevalence of human papillomavirus (HPV) 16 than females in oral rinse samples. The objective of the present study was to examine the relationship between HPV16 viral load and clinical factors, including remaining teeth, denture use and numbers of oral bacteria. A total of 124 patients (48 males and 76 females; mean age, 61.6 years; age range, 20-97 years) who visited the Department of Oral and Maxillofacial Reconstructive Surgery of Hiroshima University Hospital (Hiroshima, Japan) between November 2016 and August 2017 were analyzed. None of the patients had evidence of oral cancer or pre-malignant lesions, including epithelial dysplasia and leukoplakia. Quantitative polymerase chain reaction (qPCR) analysis was employed to examine the number of HPV16 viral copies. Furthermore, the number of oral bacteria was determined using the dielectrophoretic impedance measurement method. HPV16 was below the limit of detection in qPCR findings for samples obtained from 30 of the 124 subjects, thus the association of HPV16 viral copy number with clinical parameters was examined in the remaining 94 patients. The average number of HPV16 E6 DNA copies was $1.65 \pm 3.47$ copies/cell (range, $0.07-25.3$ copies/cell) and was significantly higher in subjects with a high oral bacteria count $\left[\geq 10^{6.5}\right.$ colony forming unit (CFU)/ml] than in those with a low count $\left(<10^{6.5} \mathrm{CFU} / \mathrm{ml}\right)(0.79 \pm 0.98$ vs. $2.06 \pm 4.11$ copies/cell; $\mathrm{P}=0.030$ ). The present results indicated that HPV16 viral load may be related to an increased bacterial number in the oral cavity. Further investigations are required to clarify the correlation between oral HPV load and oral hygiene status.
\end{abstract}

Correspondence to: Dr Hideo Shigeishi, Department of Public Oral Health, Program of Oral Health Sciences, Graduate School of Biomedical and Health Sciences, Hiroshima University, 1-2-3 Kasumi, Hiroshima 734-8553, Japan

E-mail: shige@hiroshima-u.ac.jp

Abbreviations: HPV, human papillomavirus; ERV3-1, human endogenous retrovirus group 3 member 1

Key words: HPV16, viral copy number, oral bacterial count

\section{Introduction}

Human papillomavirus (HPV) infection is a major cause of cervical cancer and is also associated with the development of oropharyngeal cancer and prognosis in affected patients (1-3). To date, $>170$ HPV genotypes have been reported, of which $\sim 50$ are known to infect the anogenital and oral mucosa regions (4-6). As for oral cancer, a previous study conducted by the present research group indicated that $\sim 80 \%$ of patients with HPV16-positive moderate epithelial dysplasia progressed to oral squamous cell carcinoma (OSCC), indicating that oral HPV16 infection may also be associated with the development of oral cancer (7). However, few epidemiologic studies have focused on oral HPV prevalence in non-OSCC cases and the risk factors for oral HPV infection have not been fully elucidated. Hence, we previously performed a meta-analysis, which demonstrated that sexual behavior and smoking are significant risk factors for oral HPV infection in cancer-free individuals (8). In addition, other factors, such as poor oral hygiene related to periodontitis and gingivitis, have been indicated to be associated with oral HPV infection (8).

In order to examine the correlation between HPV 16 prevalence in the oral cavity and clinical factors, we also investigated HPV16 prevalence using oral rinse samples obtained from subjects without oral cancer (9). Notably, a significantly higher prevalence was found in males than in females, indicating a sex-specific susceptibility to HPV16 infection. As for the cervix, increased HPV16 load may be predictive of HPV infection persistence that eventually leads to malignancy (10). However, the relationship between oral HPV16 viral load and oral hygiene status was not fully elucidated in the previous study. In the present preliminary investigation, HPV16 viral load in the oral cavity and its association with oral bacteria count was examined. Furthermore, 16S ribosomal (r)RNA gene sequencing for taxonomic classification of harbored bacteria was performed in order to investigate the association of HPV16 viral load with oral microbiome composition.

\section{Patients and methods}

Subjects. A total of 124 patients (48 males and 76 females; mean age, 61.6 years; age range, 20-97 years) who visited the Department of Oral and Maxillofacial Reconstructive 
Surgery of Hiroshima University Hospital (Hiroshima, Japan) between November 2016 and August 2017 were enrolled in the present study. None of the patients had evidence of oral cancer or pre-malignant lesions (e.g., epithelial dysplasia or leukoplakia). The present study design was approved by the Ethics Committee of Hiroshima University and all participants signed an informed consent agreement.

Oral rinse sample processing and DNA extraction. Briefly, the subjects were asked to rinse their mouth with $10 \mathrm{ml}$ saline for $30 \mathrm{sec}$ and then expectorate into a sterile 15-ml Falcon tube. Immediately after collection, all samples were centrifuged at $3,000 \mathrm{x} \mathrm{g}$ for $10 \mathrm{~min}$ at $4^{\circ} \mathrm{C}$, the supernatant was decanted and the pellets were stored at $-80^{\circ} \mathrm{C}$ until further processing. Finally, DNA was extracted using a bead-beating tube (cat. no. A29158; Thermo Fisher Scientific, Inc., Waltham, MA, USA), according to the manufacturer's protocol, and purified using a PureLink ${ }^{\mathrm{TM}}$ Microbiome DNA Purification kit (Thermo Fisher Scientific, Inc.), which enables purification of host and microbial DNA from a wide variety of sample types.

Quantitation of human cell numbers. The human endogenous retrovirus group 3 member 1 (ERV3-1) gene was employed to quantitate human cells using a quantitative polymerase chain reaction (qPCR) assay. Using a previously reported method (9), serial 10-fold dilutions of the pUC57 vector inserted into the ERV3-1 genome (Hokkaido System Science Co., Ltd., Sapporo, Japan) were generated with copy numbers ranging from $10^{0}-10^{9}$. Quantitation of DNA levels was determined using a CFX connect real-time PCR detection system (Bio-Rad Laboratories, Inc., Hercules, CA, USA) and SYBR-Green PCR Master mix (Toyobo Life Science, Osaka, Japan), with a reaction mixture containing $1.0 \mu 1$ DNA, 9.0 $\mu$ l SYBR-Green mix and $10 \mu \mathrm{mol}$ of each pair of oligonucleotide primers. G3PDH was used as a reference gene for PCR analysis. The primer sequences were as follows: ERV-3 sense, 5'-CATGGGAAGCAAGGGAACTAATG-3' and antisense, 5'-CCCAGCGAGCAATACAGAATTT-3'; and G3PDH sense, 5'-ACCACAGTCCATGCCATCAC-3' and antisense, 5'-TCCACCACCCTGTTGCTGTA-3'. Amplifications were performed with initial melting at $95^{\circ} \mathrm{C}$ for $5 \mathrm{~min}$, followed by 40 cycles of denaturation at $95^{\circ} \mathrm{C}$ for $30 \mathrm{sec}$, annealing at $56^{\circ} \mathrm{C}$ for $30 \mathrm{sec}$ and extension at $72^{\circ} \mathrm{C}$ for $1 \mathrm{~min}$. A standard curve indicating the cycle threshold (CT) value vs. ERV3-1 copy number was obtained to estimate the number of human cells in each sample.

HPV16 viral copy quantitation. qPCR assays were performed to determine HPV16 viral load in the samples. Using a previously reported method (9), a 200-bp fragment within HPV16 E6 genome was prepared, which was then cloned into a pUC57 vector (GenScript Biotech Corporation, Piscataway, NJ, USA). Serial 10-fold dilutions of the vector were made with copy numbers ranging from $10^{3}-10^{9}$. Those 10 -fold dilutions were used to generate a standard curve, which indicated the CT value vs. copy number of HPV16 E6. DNA samples extracted from 5,000-10,000 human cells were prepared from each PCR mixture and the HPV16 sequence was examined by PCR with type-specific primers. The primer sequences for HPV16 E6 were as follows: Sense, 5'-AAGGGCGTAACCGAAATCGGT-3' and antisense, 5'-GTTTGCAGCTCTGTGCATA-3'. A positive control containing HPV16 DNA extracted from CaSki cells [American Type Culture Collection (ATCC), Manassas, VA, USA] and a negative control containing DNA purified from the HPV-negative cell line HTB31 (ATCC) were used for the PCR reactions. Quantitation of DNA levels was determined using a CFX connect real-time PCR detection system and SYBR-Green PCR Master mix. Amplifications were performed with initial melting at $95^{\circ} \mathrm{C}$ for $5 \mathrm{~min}$, followed by 40 cycles of denaturation at $95^{\circ} \mathrm{C}$ for $30 \mathrm{sec}$, annealing at $58^{\circ} \mathrm{C}$ for $30 \mathrm{sec}$ and extension at $72^{\circ} \mathrm{C}$ for $1 \mathrm{~min}$. G3PDH was used as a reference gene for PCR analysis.

Analysis of bacterial numbers. The number of oral bacteria was determined using a Bacterial Counter (DU-AA01 NP-H; Panasonic Healthcare Co., Ltd., Tokyo, Japan), which is an oral bacteria detection device that employs the dielectrophoretic impedance measurement method with a microelectrode chip on which bacteria in liquids are captured by dielectrophoresis (11). The impedance change is converted to bacterial concentration $/ \mathrm{ml}$ of each sample (CFU/ml). Samples were obtained from the tongue surface using a cotton swab (Panasonic Healthcare Co., Ltd.), according to the manufacturer's protocol, before collecting the oral rinse sample. Bacterial numbers were defined as follows: Level $1\left(<10^{5} \mathrm{CFU} / \mathrm{ml}\right)$, level $2\left(\geq 10^{5}\right.$ and $\left.<10^{6} \mathrm{CFU} / \mathrm{ml}\right)$, level $3\left(\geq 10^{6}\right.$ and $\left.<10^{6.5} \mathrm{CFU} / \mathrm{ml}\right)$, level 4 $\left(\geq 10^{6.5}\right.$ and $\left.<10^{7.0} \mathrm{CFU} / \mathrm{ml}\right)$, level $5\left(\geq 10^{7.0}\right.$ and $\left.<10^{7.5} \mathrm{CFU} / \mathrm{ml}\right)$, level $6\left(\geq 10^{7.5}\right.$ and $\left.<10^{8.0} \mathrm{CFU} / \mathrm{ml}\right)$ and level $7\left(\geq 10^{8.0} \mathrm{CFU} / \mathrm{ml}\right)$.

16S rRNA gene sequencing for taxonomic classification of bacteria. The V3-V4 region of the bacterial 16S rRNA gene was amplified from DNA in the oral rinse samples using forward primer 341F (5'-TCGTCGGCAGCGTCAGAT GTGTATAAGAGACAGCCTACGGGNGGCWGCAG-3') and reverse primer 806R (5'-GTCTCGTGGGCTCGGAGATG TGTATAAGAGACAGGGACTACGVGGGTWTCTAAT-3'). Amplicons were generated, cleaned, indexed and sequenced according to the 16S Metagenomic Sequencing Library Preparation, part 15044223 , Rev. B. Briefly, the initial PCR reaction contained $10.0 \mathrm{ng}$ DNA, $2.5 \mu 1$ 16S V3-V4 Primer mix (10X), $12.5 \mu 12$ X Gflex PCR Buffer and $0.5 \mu 1 \mathrm{Tks}$ Gflex DNA Polymerase (Takara Biotechnology Co., Ltd., Dalian, China) in a total volume of $25 \mu \mathrm{l}$. Amplifications were performed with initial melting at $94^{\circ} \mathrm{C}$ for $1 \mathrm{~min}$, followed by 28 cycles of denaturation at $98^{\circ} \mathrm{C}$ for $10 \mathrm{sec}$, annealing at $50^{\circ} \mathrm{C}$ for $15 \mathrm{sec}$ and extension at $68^{\circ} \mathrm{C}$ for $15 \mathrm{sec}$ using a Takara PCR Thermal Cycler Dice ${ }^{\circledR}$ Touch device (Takara Biotechnology Co., Ltd.). The resultant PCR product was cleaned using an Agencourt AMPure XP (Beckman Coulter, Inc., Brea, CA, USA). Samples were multiplexed with a dual-index approach using a Nextera XT Index kit (Illumina, Inc., San Diego, CA, USA). Briefly, the second PCR reaction was composed of $2.0 \mu 1$ PCR products, $2.5 \mu 1$ index primer 1 (5'-CAAGCAGAAGACGGCA TACGAGATGTAGAGGAGTCTCGTGGGCTCGG-3') and 2 (5'-ATGATACGGCGACCACCGAGATCTACACAGAGTAG ATCGTCGGCAGCGTC-3'), $2.5 \mu 1$ 2X Gflex PCR Buffer and $0.5 \mu \mathrm{l}$ Tks Gflex DNA Polymerase in a total volume of $25.0 \mu \mathrm{l}$. Amplifications were performed with initial melting at $94^{\circ} \mathrm{C}$ for $1 \mathrm{~min}$, followed by 8 cycles of denaturation at $98^{\circ} \mathrm{C}$ for $10 \mathrm{sec}$, annealing at $60^{\circ} \mathrm{C}$ for $15 \mathrm{sec}$ and extension at $68^{\circ} \mathrm{C}$ for $15 \mathrm{sec}$. 
Table I. Association between oral HPV16 E6 copy number and clinical parameters.

\begin{tabular}{|c|c|c|c|}
\hline Clinical characteristics & $\mathrm{n}$ & HPV16 copy number/cell & P-value \\
\hline \multicolumn{4}{|l|}{ Sex } \\
\hline Male & 38 & $1.52 \pm 3.11$ & \multirow[t]{2}{*}{0.76} \\
\hline Female & 56 & $1.75 \pm 3.72$ & \\
\hline \multicolumn{4}{|l|}{ Age, years } \\
\hline $20-29$ & 9 & $2.27 \pm 2.12$ & \multirow[t]{7}{*}{0.39} \\
\hline $30-39$ & 8 & $0.53 \pm 0.37$ & \\
\hline $40-49$ & 4 & $2.64 \pm 2.67$ & \\
\hline $50-59$ & 12 & $0.60 \pm 0.52$ & \\
\hline $60-69$ & 22 & $1.15 \pm 1.29$ & \\
\hline $70-79$ & 27 & $1.20 \pm 1.93$ & \\
\hline $80-89$ & 12 & $4.64 \pm 8.43$ & \\
\hline \multicolumn{4}{|c|}{ Number of remaining teeth } \\
\hline$\geq 20$ & 68 & $1.33 \pm 2.64$ & \multirow[t]{3}{*}{0.23} \\
\hline $10-19$ & 14 & $1.03 \pm 2.10$ & \\
\hline $0-9$ & 12 & $3.33 \pm 7.13$ & \\
\hline \multicolumn{4}{|l|}{ Denture use } \\
\hline Non-denture user & 72 & $1.43 \pm 2.57$ & \multirow[t]{3}{*}{0.43} \\
\hline Partial denture & 18 & $1.40 \pm 2.22$ & \\
\hline Full denture & 4 & $6.94 \pm 12.3$ & \\
\hline \multicolumn{4}{|l|}{ Bacteria count } \\
\hline Level 2 & 6 & $0.62 \pm 0.47$ & \multirow[t]{5}{*}{0.14} \\
\hline Level 3 & 24 & $0.83 \pm 1.07$ & \\
\hline Level 4 & 41 & $1.92 \pm 4.15$ & \\
\hline Level 5 & 20 & $1.53 \pm 1.97$ & \\
\hline Level 6 & 3 & $7.48 \pm 10.1$ & \\
\hline
\end{tabular}

Mann Whitney U or Kruskal-Wallis tests were used for statistical analysis. P-values indicate the difference between the different groups for each clinical characteristic. HPV, human papillomavirus.

The final library was subjected to paired-end sequencing with a MiSeq Reagent kit v.3 on the Illumina MiSeq platform (both from Illumina, Inc.). Sequencing data were denoised, low quality sequences were removed and the sequences were clustered into operational taxonomic units (OTUs) at 97\% identity using the CD-HIT-OTU pipeline (12). Subsequently, taxonomy classification was analyzed using the Quantitative Insights into Microbial Ecology pipeline, as previously reported (13).

Statistical analysis. Data were presented as the mean \pm standard deviation of three independent experiments. Statistical analysis was performed using SPSS version 24.0 (IBM Corp., Armonk, NY, USA). Mann Whitney U or Kruskal-Wallis tests were used to evaluate significant differences regarding HPV16 copy numbers and clinical factors. Mann Whitney U tests with Bonferroni's correction were employed following Kruskal-Wallis tests. $\mathrm{P}<0.05$ was considered to indicate a statistically significant difference.

\section{Results}

Quantitation of HPV16 E6 viral copy number using qPCR. HPV16 viral copy number was determined in a total of 124 oral rinse samples using qPCR, then the number of HPV16 DNA copies was evaluated as copy number/human cell using a standard curve. The CT value was identified to be below the detection limit in the standard curve in 30 of the 124 samples, which were assessed as HPV16 DNA not determined and were not included in further analysis. Thus, the association of HPV16 viral copy number with clinical parameters were examined in 94 cases.

The average number of HPV16 E6 viral copies was $1.65 \pm 3.47$ copies/cell (range, 0.07-25.3 copies/cell). The association between the number of HPV16 viral copies and clinical parameters were then examined; however, no statistically significant association was identified (Table I). With regards to sex, there was no significant difference in the number of HPV16 E6 viral copies between males (1.52 \pm 3.11 copies) and females $(1.75 \pm 3.72$ copies). Regarding age, subjects $\geq 80$ years old demonstrated the highest mean number of HPV16 compared with the other age groups. Notably, individuals using a full denture were revealed to have a higher mean number of HPV16 viral copies than those with a partial denture or who did not use a denture. Although a difference was observed between the groups for age and denture use, these differences were not significant. 


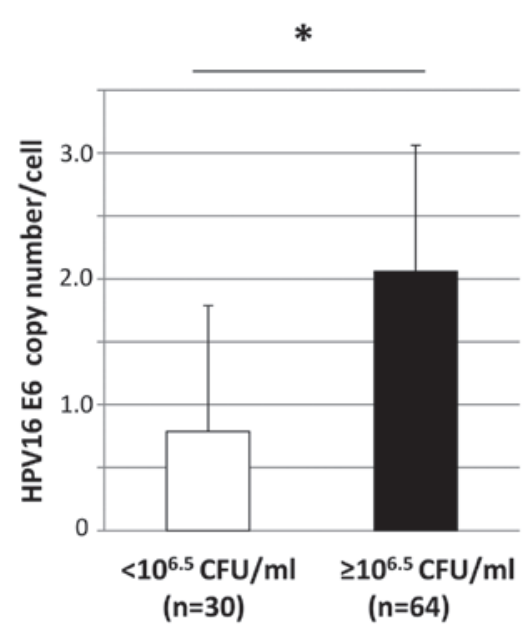

Figure 1. Association between HPV16 viral copy number and oral bacteria count. The number of HPV16 viral copies was higher in subjects with an elevated oral bacteria count $\left(\geq 10^{6.5} \mathrm{CFU} / \mathrm{ml} ; \mathrm{n}=64\right)$ than in those with a low bacteria count $\left(<10^{6.5} \mathrm{CFU} / \mathrm{ml} ; \mathrm{n}=30\right)$. A significant difference in regard to the number of viral copies was observed between the groups with a low vs. high oral bacteria count $\left(0.79 \pm 0.98\right.$ vs. $2.06 \pm 4.11$ copy numbers/cell). ${ }^{*} \mathrm{P}=0.030$ as indicated, according to the Mann Whitney U test. HPV, human papillomavirus.

Association between HPV16 E6 viral copy number and oral bacteria. The mean number of oral bacteria was

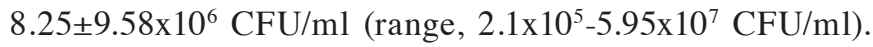
The number of bacteria was classified as levels 1-7 and the numbers of viral copies according to the different bacterial levels are summarized in Table I. The number of HPV16 viral copies was significantly higher in individuals with a high level of oral bacteria ( $\geq 10^{6.5} \mathrm{CFU} / \mathrm{ml}$; levels $4-6$ ) than in those with a low level $\left(<10^{6.5} \mathrm{CFU} / \mathrm{ml}\right.$; levels 2 and 3$)(0.79 \pm 0.98$ vs. 2.06 \pm 4.11 copy numbers/cell; $\mathrm{P}=0.030$; Fig. 1$)$.

Furthermore, analysis of 16s rRNA in bacterial flora was performed using the oral rinse samples to examine microbiome diversity in cases with a high number of HPV16 viral copies. The present findings of 5 cases with high HPV16 viral copy numbers (>5.0 HPV16 DNA copy/cell) were compared with those of 5 cases with low HPV16 viral copy numbers $(<0.5$ HPV16 DNA copy/cell). At the genus level, a total of 41 genera were identified in the groups, of which Actinomyces, Streptococcus, Prevotella, Veillonella, Gemella, Fusobacterium, Neisseria, Rothia and Haemophilus constituted $>70 \%$ in both. Streptococcus was most commonly detected in both groups. Notably, except for Streptococcus, no other genus was found in $>25 \%$ of the cases with a low HPV16 viral copy number (Fig. 2). In contrast, Streptococcus comprised $75.8 \%$ in one case in the high HPV16 viral copy group, while Actinomyces (25.8\%) and Veillonella (16.3\%) were frequently detected in another case in the high HPV16 viral copy group (Fig. 2). Additionally, an increased percentage of gram-negative anaerobic bacteria, such as Prevotella (15.8\%), was identified in a case in the group with a high number of HPV16 viral copies (Fig. 2).

\section{Discussion}

We previously performed a meta-analysis of oral HPV prevalence to clarify risk factors related to oral HPV infection in healthy individuals. The results suggested that changes in the oral environment due to sexual behavior (i.e., oral sex and homosexuality in men) and smoking were significantly
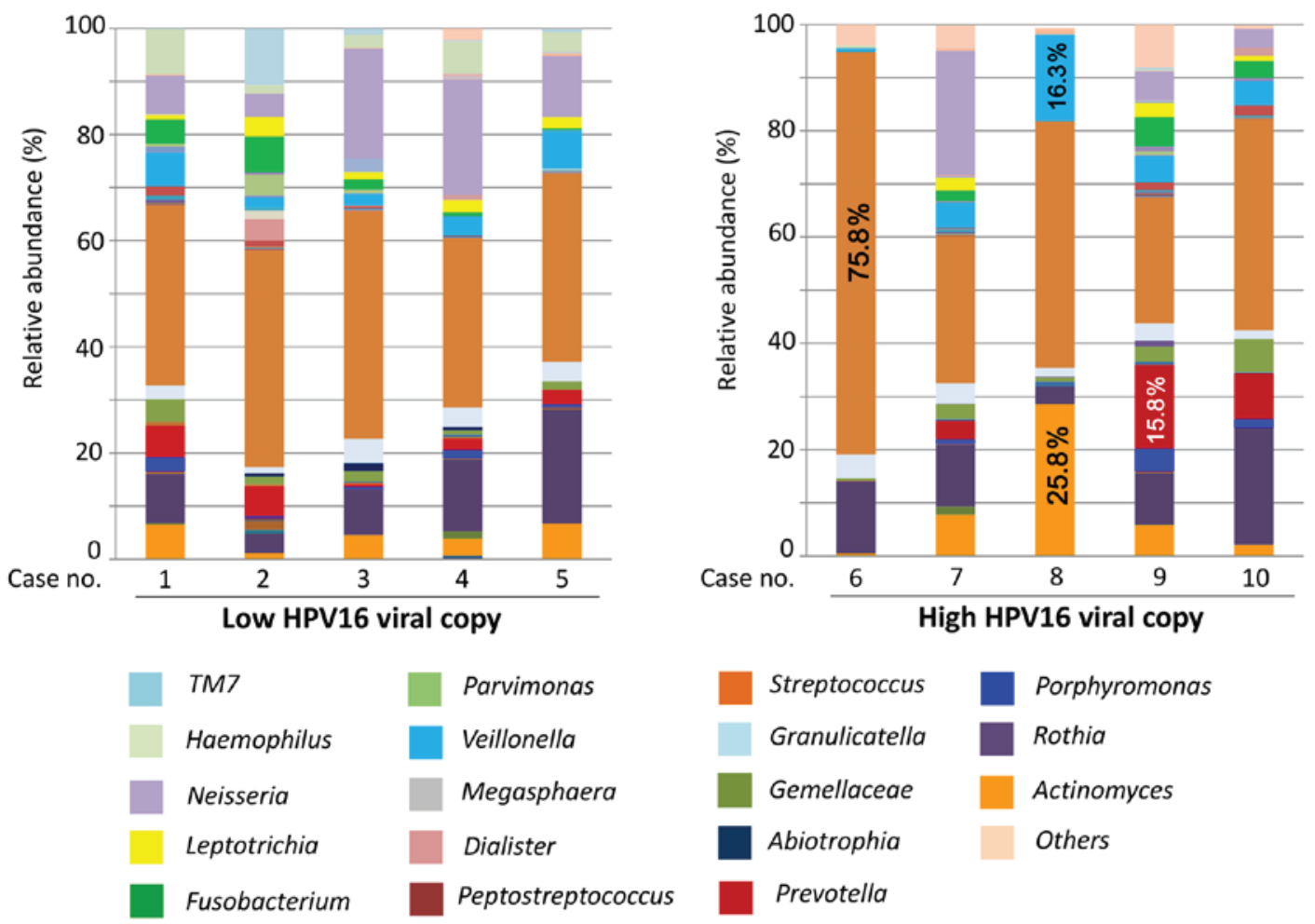

Figure 2. Bacterial flora analysis of the 16S ribosomal RNA gene in oral rinse samples. The compositions of oral bacteria in subjects with an elevated number of HPV16 viral copies (>5.0 HPV16 DNA copies/cell; n=5) and those with a low HPV16 viral copy number (<0.5 HPV16 DNA copies/cell; n=5) are demonstrated. HPV, human papillomavirus. 
associated with oral HPV infection, whereas alcohol consumption was not a factor (8). As for smoking, suppression of the oral immune system caused by chemical substances in tobacco may be involved in oral HPV infection (14). Notably, female smokers have been demonstrated to have a significantly higher prevalence of HPV infection as compared to male smokers (15). However, a significant association between smoking and HPV viral copy number was not identified in the present study (data not shown). On the other hand, gingivitis and periodontal disease are also potential risk factors for oral HPV infection (16-18), indicating that poor oral hygiene may induce the risk of HPV infection in gingival pockets. A comparison of denture wearers and non-wearers demonstrated a higher HPV infection rate in the former, indicating that mucosal injury or poor dental hygiene associated with denture use is importantly involved in HPV infection $(8,9)$. In the present study, subjects who wore full dentures exhibited a higher number of HPV copies than partial denture and non-denture users; however, the difference was not significant. Thus, full denture use may be a risk factor for oral HPV infection and HPV DNA replication in elderly individuals.

The present study revealed that the levels of oral bacteria in samples from the tongue dorsum were significantly associated with increased HPV copy number. However, there was no significant association between the levels of oral bacteria and sex, age, remaining teeth or denture use (data not shown). In addition, increased percentages of periodontal pathogens, including Veillonella and Prevotella, were detected in individuals with a high number of HPV copies as compared with those with a low number. These findings indicate that increased HPV16 viral replication may be related to the development of an unbalanced microbiome and increased pathogenic bacteria in the oral cavity. It has been speculated that an inflamed periodontal pocket serves as a reservoir for HPV and induces HPV infection (19). Whether periodontal disease is related to oral HPV infection remains controversial (20-22), though the presence of such inflammatory diseases may serve an important role in the biology of HPV infection. On the other hand, HPV may be involved in deterioration associated with periodontal disease (i.e., increased alveolar bone loss) in accordance with other pathogenic factors (18). Similarly, the presence of human viruses, including the herpes virus and Epstein-Barr virus, in periodontal sites may worsen periodontal disease $(23,24)$. It is thus considered that human viral factors may serve a vital role in modulation of inflammatory disease in the oral cavity, such as periodontitis, as well as harbored bacteria.

The oral cavity harbors characteristic microbiomes in different sites, including the gingiva, tongue surface, palate, buccal mucosa and teeth $(25,26)$. Thus, it is likely that the microbiome in an oral rinse sample is composed of a variety of bacteria from different oral regions. The tongue surface has been demonstrated to exhibit a relatively stable bacterial microbiome with a composition very similar to that of saliva $(27,28)$. The present study compared differences in bacterial composition between oral rinse samples and different oral sites. Notably, the oral rinse samples demonstrated a bacterial composition similar to that of the tongue surface (data not shown), indicating that the microbiome obtained by oral rinsing is predominantly associated with that of the tongue surface. However, it remains uncertain whether HPV virus load is affected by an unbalanced bacterial composition and elevated levels of anaerobic bacteria. Additional cluster analyses of microbial communities are essential, as such findings should provide greater insight into the relationship between specific oral bacteria and HPV.

We previously employed PCR assays to detect HPV16 DNA in oral rinse and gargle samples to examine differences between the oral cavity and oropharynx regarding HPV16 prevalence (9). Notably, a higher prevalence of HPV16 in gargle samples was observed than in the oral rinse samples in the previous study, indicating that the oropharynx is more susceptible to HPV16 infection. Furthermore, the number of HPV16 copies was significantly higher in the gargle samples than in the oral rinse samples from those subjects, indicating that the oropharynx is more susceptible to HPV16 infection and HPV16 gene amplification is more common here as compared with the oral cavity (9). HPV may be trapped in tonsillar crypts and then invade basal cells in the reticulated epithelium, resulting in HPV infection (8). In a study on patients with head and neck squamous cell carcinoma, the HPV16 genome copy number was much higher in samples from patients with oropharyngeal cancer than in those with oral cancer, supporting the notion that the oropharynx is a more favorable site for HPV16 infection and replication as compared with other head and neck regions (29). It is possible that the variability of HPV16 infection rate among different sites may be associated with the biological features of HPV-related cancer.

In conclusion, the present results suggested that HPV16 viral load may be associated with an increased bacterial number in the oral cavity. Further investigations are required to clarify the correlation between oral HPV load and oral hygiene status. As oral HPV infection is considered to be associated with poor oral hygiene, focus on oral health care and smoking cessation may serve a vital role in its prevention. For prevention strategies and treatment of HPV-related oral cancer, it is necessary to clarify the biological features of oral HPV and its environmental influence in the near future.

\section{Acknowledgements}

The present study was supported by a Grant-in-aid for Scientific Research (C) (grant no. 15K11290) from the Ministry of Education, Culture, Sports and Technology of Japan.

\section{References}

1. Dürst M, Gissmann L, Ikenberg H and zur Hausen H: A papillomavirus DNA from a cervical carcinoma and its prevalence in cancer biopsy samples from different geographic regions. Proc Natl Acad Sci USA 80: 3812-3815, 1983.

2. Ang KK, Harris J, Wheeler R, Weber R, Rosenthal DI, NguyenTân PF, Westra WH, Chung CH, Jordan RC, Lu C, et al: Human papillomavirus and survival of patients with oropharyngeal cancer. N Engl J Med 363: 24-35, 2010.

3. Smeets SJ, Braakhuis BJ, Abbas S, Snijders PJ, Ylstra B van de Wiel MA, Meijer GA, Leemans CR and Brakenhoff RH: Genome-wide DNA copy number alterations in head and neck squamous cell carcinomas with or without oncogene-expressing human papillomavirus. Oncogene 25: 2558-2564, 2006.

4. Ma Y, Madupu R, Karaoz U, Nossa CW, Yang L, Yooseph S, Yachimski PS, Brodie EL, Nelson KE and Pei Z: Human papillomavirus community in healthy persons, defined by metagenomics analysis of human microbiome project shotgun sequencing data sets. J Virol 88: 4786-4797, 2014. 
5. de Villiers EM: Cross-roads in the classification of papillomaviruses. Virology 445: 2-10, 2013.

6. IARC: Human papillomaviruses. A review of human carcinogens - part B: Biological agents. IARC Monogr Eval Carcinog Risks Hum 100B: 1-475, 2011.

7. Sugiyama M, Bhawal UK, Dohmen T, Ono S, Miyauchi M and Ishikawa T: Detection of human papillomavirus-16 and HPV-18 DNA in normal, dysplastic, and malignant oral epithelium. Oral Surg Oral Med Oral Pathol Oral Radiol Endod 95: 594-600, 2003

8. Shigeishi H and Sugiyama M: Risk factors for oral human papillomavirus infection in healthy individuals: A systematic review and meta-analysis. J Clin Med Res 8: 721-729, 2016.

9. Shigeishi H, Sugiyama M, Ohta K, Rahman MZ and Takechi M: Higher prevalence and gene amplification of HPV16 in oropharynx as compared to oral cavity. J Appl Oral Sci 24: 397-403, 2016.

10. Trevisan A, Schlecht NF, Ramanakumar AV, Villa LL and Franco EL; Ludwig-McGill Study Group: Human papillomavirus type 16 viral load measurement as a predictor of infection clearance. J Gen Virol 94: 1850-1857, 2013.

11. Hamada R, Suehiro J, Nakano M, Kikutani T and Konishi K Development of rapid oral bacteria detection apparatus based on dielectrophoretic impedance measurement method. IET Nanobiotechnol 5: 25-31, 2011

12. Li W, Fu L, Niu B, Wu S and Wooley J: Ultrafast clustering algorithms for metagenomic sequence analysis. Brief Bioinform 13: 656-668, 2012.

13. Caporaso JG, Kuczynski J, Stombaugh J, Bittinger K, Bushman FD, Costello EK, Fierer N, Peña AG, Goodrich JK, Gordon JI, et al: QIIME allows analysis of high-throughput community sequencing data. Nat Methods 7: 335-336, 2010.

14. Kreimer AR, Pierce Campbell CM, Lin HY, Fulp W, Papenfuss MR, Abrahamsen M, Hildesheim A, Villa LL, Salmerón JJ, Lazcano-Ponce E and Giuliano AR: Incidence and clearance of oral human papillomavirus infection in men: The HIM cohort study. Lancet 382: 877-887, 2013.

15. Gillison ML, Broutian T, Pickard RK, Tong ZY, Xiao W, Kahle L, Graubard BI and Chaturvedi AK: Prevalence of oral HPV infection in the United States, 2009-2010. JAMA 307: 693-703, 2012.

16. Hormia M, Willberg J, Ruokonen H and Syrjänen S: Marginal periodontium as a potential reservoir of human papillomavirus in oral mucosa. J Periodontol 76: 358-363, 2005.

17. Engels EA, Biggar RJ, Hall HI, Cross H, Crutchfield A, Finch JL, Grigg R, Hylton T, Pawlish KS, McNeel TS and Goedert JJ: Cancer risk in people infected with human immunodeficiency virus in the United States. Int J Cancer 123: 187-194, 2008.

18. Tezal M, Sullivan Nasca M, Stoler DL, Melendy T, Hyland A, Smaldino PJ, Rigual NR and Loree TR: Chronic periodontitishuman papillomavirus synergy in base of tongue cancers. Arch Otolaryngol Head Neck Surg 135: 391-396, 2009.
19. Kines RC, Thompson CD, Lowy DR, Schiller JT and Day PM: The initial steps leading to papillomavirus infection occur on the basement membrane prior to cell surface binding. Proc Natl Acad Sci USA 106: 20458-63, 2009.

20. Dayakar MM, Shipilova A and Gupta D: Periodontal pocket as a potential reservoir of high risk human papilloma virus: A pilot study. J Indian Soc Periodontol 20: 136-140, 2016.

21. Fuster-Rossello L, Ribotta E, Cuffini C and Fuster-Juan M: Human papilloma virus in oral mucosa and its association with periodontal status of gynecologically infected women. Acta Odontol Latinoam 27: 82-88, 2014.

22. Wiener RC, Sambamoorthi U and Jurevic RJ: Association of periodontitis and human papillomavirus in oral rinse specimens: Results from the National Health and Nutrition Survey 2009-2012. J Am Dent Assoc 146: 382-389, 2015.

23. Idesawa M, Sugano N, Ikeda K, Oshikawa M, Takane M, Seki K and Ito K: Detection of Epstein-Barr virus in saliva by real-time PCR. Oral Microbiol Immunol 19: 230-232, 2004.

24. Saygun I, Kubar A, Sahin S, Sener K and Slots J: Quantitative analysis of association between herpesviruses and bacterial pathogens in periodontitis. J Periodontal Res 43: 352-359, 2008.

25. Segata N, Haake SK, Mannon P, Lemon KP, Waldron L, Gevers D, Huttenhower $\mathrm{C}$ and Izard $\mathrm{J}$ : Composition of the adult digestive tract bacterial microbiome based on seven mouth surfaces, tonsils, throat and stool samples. Genome Biol 13: R42, 2012.

26. Bik EM, Long CD, Armitage GC, Loomer P, Emerson J, Mongodin EF, Nelson KE, Gill SR, Fraser-Liggett CM and Relman DA: Bacterial diversity in the oral cavity of 10 healthy individuals. ISME J 4: 962-974, 2010.

27. Zhou Y, Gao H, Mihindukulasuriya KA, La Rosa PS, Wylie KM, Vishnivetskaya T, Podar M, Warner B, Tarr PI, Nelson DE, et al: Biogeography of the ecosystems of the healthy human body. Genome Biol 14: R1, 2013.

28. Takeshita T, Yasui M, Tomioka M, Nakano Y, Shimazaki Y and Yamashita Y: Enteral tube feeding alters the oral indigenous microbiota in elderly adults. Appl Environ Microbiol 77: 6739-6745, 2011.

29. Ndiaye C, Mena M, Alemany L, Arbyn M, Castellsagué X, Laporte L, Bosch FX, de Sanjosé S and Trottier H: HPV DNA, E6/E7 mRNA, and p16INK4a detection in head and neck cancers: A systematic review and meta-analysis. Lancet Oncol 15: 1319-1331, 2014. 